\title{
Media, technology, and the sins of memory
}

\author{
Daniel L. Schacter \\ Department of Psychology, Harvard University, Cambridge, MA, USA \\ Corresponding author: Daniel L. Schacter, email: dls@wjh.harvard.edu
}

\begin{abstract}
Human memory is prone to error and distortion. It has been proposed that memory's misdeeds can be classified into seven categories or 'sins'. This article discusses the impact of media and technology on four memory sins: transience (forgetting over time), absent-mindedness (lapses in attention that produce forgetting), misattribution (attributing a memory to the wrong source), and suggestibility (implanted memories). Growing concerns have been expressed about the negative impact of media and technology on memory. With respect to transience, I review research regarding the impact of the Internet (ie, Google), GPS, and photographs. Studies have documented impaired memory following specific tasks on which people rely on media/technology (eg, poor memory for a route after using GPS), but have revealed little evidence for broader impairments (eg, generally impaired memory in GPS users), and have also documented some mnemonic benefits (eg, reviewing photos of past experiences). For absent-mindedness, there is strong evidence that media multitasking is associated with poor memory for a target task (eg, a lecture) because of attentional lapses, suggesting evidence that chronic media multitasking could be associated with broader memory problems, and emerging evidence that technology can help to reduce certain kinds of absent-minded errors. Regarding misattribution and suggestibility, there is clear evidence that manipulated or misleading photos are associated with false memories for personal events and fake news, but no evidence of broader effects on susceptibility to memory distortion. Further study of the impact of media and technology on the memory sins is a fruitful pursuit for interdisciplinary studies.
\end{abstract}

Keywords: memory; forgetting; false memories; media; technology; Internet; fake news

Attempting to understand the nature of memory has long been of interest to scholars working in a wide range of disciplines including psychology, neuroscience, philosophy, computer science, history, law, sociology, and others. Memory studies within each of these disciplines remain vibrant, but interdisciplinary approaches to memory have also proven highly fruitful. To take just one example from the areas in which I have worked, the emergence of cognitive neuroscience during the 1980s and 1990s, combining the tools and theoretical frameworks of cognitive psychology and neuroscience, has led to an explosion in our knowledge of how psychological processes described in cognitive models of memory map onto underlying neural processes and networks (for recent overviews, see Poeppel et al 2020; Slotnick 2017).

As marked by the launch of $M M M$, the time is now right for encouraging an interdisciplinary approach to memory and media, one that draws on the wide range of disciplines that have a unique and necessary perspective to offer regarding how 
memory is impacted by various forms of media and technology. In the present article, I focus on a characteristic of human memory that has been acknowledged and explored across a broad range of disciplines: human memory is not a perfect record of experience, but instead is prone to various kinds of errors, lapses, and distortions. Within experimental psychology, this awareness of memory errors dates to the pioneering studies of Ebbinghaus (1964 [1885]), who produced the first systematic evidence of a forgetting curve, and is perhaps most famously associated with the research of Bartlett (1932), who documented theoretically revealing memory distortions in his studies of how people remember stories.

Two decades ago, I attempted to organise existing knowledge of memory's imperfections by arguing that they can be classified into seven basic categories, which by analogy to the ancient seven deadly sins, I called the seven sins of memory (Schacter 1999, 2001). The first three are 'sins of omission' that describe different kinds of forgetting: transience (forgetting over time), absent-mindedness (memory failure that results from a lapse of attention), and blocking (temporary inaccessibility of information that is stored in memory). The next three are 'sins of commission' that describe different kinds of distortions: misattribution (attributing a memory or idea to the wrong source), suggestibility (implanted memories that result from suggestion or misinformation), and bias (retrospective distortions produced by current knowledge, beliefs, and feelings). The seventh sin, also one of commission, is persistence (intrusive or pathological remembering of events). Each of the memory sins can cause serious problems in everyday life. Nonetheless, I also argued that the seven sins do not reflect fatal flaws or evolutionary blunders in the organisation of memory; instead, they should be viewed as consequences of adaptive processes that contribute importantly to the functioning of memory in everyday life (Schacter 2001, chapt 8; for an update on the seven sins, see Schacter 2021, in press).

The seven sins are relevant to explorations of memory and media because a prominent theme in discussions of how the Internet and related forms of media or technology influence memory is that they are having a highly negative impact. This perspective is reflected in titles of recent popular press and online articles, such as 'How the Internet is ruining your memory' (Peterson 2015), 'Wait, what? New research says internet use is killing your memory' (Robitzski 2019), and 'Is technology destroying our memory?' (Stuart 2019). The Center for Humane Technology supports a 'Ledger of Harms' that provides links to research concerning costs associated with media and technology platforms, including 'Loss of crucial abilities including memory and focus' (https://ledger. humanetech.com/). The Kaspersky Lab has gone so far as to proclaim the existence of 'digital amnesia' and provided online tests to determine whether one is afflicted by the condition (http://amnesia.kaspersky.com/).

Concerns about the possibly harmful effects of media and technology on memory are not unfounded. For example, in an article cited by the 'Ledger of Harms', Sharifian and Zahodne (2020) reported a diary study of adults ranging in age from their 20s to their $70 \mathrm{~s}$, and found that on days when they reported high use of social media, participants also reported more everyday memory failures of various kinds. Viewed from the perspective of the seven sins, a question arises regarding the locus of the potential negative impact of the Internet and related forms of technology or media on memory: Which of the seven sins is impacted by technology and media, and how? My reading of the literature is that much of the doomsaying regarding the impending technology-mediated demise of memory applies to what I call the sin of transience, ie, forgetting over time. When writers proclaim that technology is 'killing' or 'ruining' memory, they usually mean that it is impairing our ability to establish new memories that endure over time, and is thereby increasing transience. 
In this article, I will first discuss the impact of various forms of technology and media on transience and attempt to draw some distinctions that I believe can be useful in refining our conceptualisation of the nature of that impact. Next, I will extend this discussion to the sin of absent-mindedness. Absent-minded memory errors result from a breakdown at the interface of attention and memory; many of these errors (eg, forgetting to pick up groceries on the way home) occur because we become preoccupied with task-unrelated concerns, and/or lack a retrieval cue or reminder that would trigger the intended action. On the one hand, activities such as media multitasking might increase the incidence of absent-minded errors (eg, Uncapher and Wagner 2018), and on the other, people can use technology as a source of retrieval cues to reduce the incidence of absent-minded errors, often referred to nowadays as cognitive offloading (Risko and Gilbert 2016). I will consider both sides of the issue. Finally, I will also briefly discuss how media and technology can impact the distortion-related sins of misattribution and suggestibility. Because I focus selectively on these four memory sins, for broader treatments of memory, media, and technology I refer the reader to excellent discussions by other memory scientists and scholars (Clinch et al 2021; Finley et al 2018; Marsh and Rajaram 2019).

\section{Transience}

\section{Internet and computer effects}

Sparrow et al (2011) reported one of the first studies to point toward an impairing effect of Internet use on memory, and their results have been prominently cited both in the scientific literature (over 1400 citations according to Google Scholar, June 2021) and in some of the popular press articles that raise alarm bells regarding the negative impact of the Internet on memory. Sparrow et al reported that when given a difficult general information question (eg, What country has a national flag that is not rectangular?), people automatically think of computers and the Internet. Their evidence for this conclusion came from a clever modification of the well-known Stroop task, in which people are slower to name the colour of a printed word when the colour is incongruent with the printed word (eg, the word 'Green' printed in blue) than when it is congruent (eg, the word 'Blue' printed in blue). Sparrow et al reported that participants were slower to name the colour of computer-related words (eg, Google, Internet) than non-computer-related words (eg, Nike, Yoplait). They suggested that this interference with colour naming indicates that people automatically think of computers and the Internet when given difficult general knowledge questions rather than searching their memories. Moreover, they found that participants showed poorer memory for trivia items that they typed into a computer when they were told that the computer would save this information than when they were instructed that the computer would delete it. However, participants did frequently remember where they saved the answers (ie, which folder) even when they failed to recall the information itself.

These findings raised the possibility that automatic reliance on computers and the Internet is having negative effects on memory. However, Marsh and Rajaram (2019) noted that they failed to find the same kind of memory-impairing effects observed by Sparrow et al (2011), and Kahn and Martinez (2020) also failed to observe such effects. Camerer et al (2018) reported a failure to replicate the so-called Google Stroop effect, ie, the interference effect in the modified Stroop task. Sparrow (2018) pointed out several differences between the replication and the original study, but a subsequent replication study by Hesselman (2020) that attempted to address those differences also failed to find evidence for the Google Stroop effect. 
Moreover, Storm and Stone (2015) reported three experiments showing a beneficial effect of relying on a computer to store information: when participants saved a pdf that contained a word list to the computer rather than attempting to memorise the words themselves, they later recalled more items from a different list of words in a second pdf presented shortly after the first pdf. This saving-enhanced memory was not observed when participants were instructed that the saving process "was potentially fallible and that sometimes they might save a file on the computer only to later find it unavailable for restudy $(2015,185)$ '. The saving-enhanced benefit also failed to emerge when the saved information did not constitute a significant memory burden (eg, a two-word list; for related research, see Giebl et al 2020). Runge et al $(2019,2020)$ replicated the saving-enhanced effect on memory for word lists, showed that it can be observed for motor materials (ie, sequences of finger movements; Runge et al 2020), and demonstrated that benefits of saving on subsequent performance extend to cognitive tasks such as solving arithmetic problems (Runge et al 2019). However, Runge et al (2020) also documented a mnemonic cost for the saved material: participants recalled fewer of the items that they were able to save to a computer than those that they could not save. There are other conditions in which offloading items to external storage can impair memory for the offloaded items on a delayed memory test, but people who are aware that there will be a delayed test can largely overcome the detrimental effects of offloading on long-term memory (Grinschgl et al 2021).

Taken together, these studies reveal a mixed pattern of results concerning retention of information over time that includes computer-related impairments, enhancements, and null effects. What seems clear, however, is that the extant data do not support farreaching claims that the Internet or computers are 'killing' or 'ruining' memory.

\section{GPS effects}

The impact of technology on memory has also been assessed in studies concerned with the effects of GPS and similar navigational aids. Behavioural studies have shown that reliance on a navigational aid impairs memory for the route in a virtual navigation task (eg, Gardony et al 2015). Additional evidence comes from an fMRI study by Javadi et al (2017). Prior to scanning, participants toured the Soho area of London and learned about its spatial layout. During scanning the following day, participants were shown a filmed simulation of Soho and engaged in two types of spatial navigation tasks: one in which they had to rely on their memories from the previous day to plan how they would navigate, and one in which they followed navigation instructions provided by the experimenters, similar to navigating based on GPS. In the condition that required memory-based navigation, there was increased activity in the hippocampus, which numerous previous studies have linked to memory and spatial navigation, and also in a part of the prefrontal cortex that had been implicated in spatial planning by earlier work. By contrast, these increases were not observed when participants relied on experimenter-provided navigation instructions that functioned as a GPS.

Because some previous research has linked hippocampal volume with the active use of spatial navigation and memory abilities (Konishi and Bohbot 2013; Maguire et al 2000; Woollett and Maguire 2011; but see also, Weisberg et al 2019), the results reported by Javadi et al (2017) are consistent with behavioural findings that relying on GPS negatively impacts memory of a navigated route, and raise the possibility that it would negatively impact spatial memory more generally. More direct evidence on this point comes from a study by Dahmani and Bohbot (2020), who examined spatial memory and navigation performance as a function of lifetime GPS experience, as assessed by a questionnaire, in a sample of 50 drivers. On two different virtual maze tasks that required spatial 
learning without GPS, they found that individuals with greater reported lifetime GPS experience showed impaired spatial navigation and memory compared to individuals with less lifetime GPS experience. While such a finding could indicate an impairing effect of GPS use on spatial memory, it could also be that individuals who rely more on GPS do so because they have poor spatial navigation and memory skills. However, Dahmani and Bohbot failed to find any relationship between GPS use and self-reported sense of direction, and they also reported effects of GPS use on spatial memory even after accounting for the effects of subjective sense of direction. In addition, Dahmani and Bohbot performed a follow-up assessment three years after initial testing with a subset of 13 participants, and found that more reliance on GPS since initial testing was associated with a steeper decline in spatial memory at follow-up. Thus, the results of Dahmani and Bohbot provide some empirical support for the idea that reliance on GPS can impair spatial memory.

\section{Photo-related effects}

A third area in which issues related to the effects of technology on transience have emerged concerns the impact of photographs on memory. Given that online platforms such as Facebook and Instagram are overrun with photos, questions concerning how taking and reviewing photographs impact memory are timely and receiving increasing attention. Research in my lab conducted during the 1990s revealed that when participants reviewed photographs of specific incidents that occurred in an earlier videotaped sequence of actions, subsequent memory for those events was improved relative to a no-review condition (Koutstaal et al 1998). More recently, benefits of photo review on subsequent memory have been documented in studies in which healthy and brain-injured participants are equipped with wearable cameras such as SenseCam, which allow people to record and later review everyday experiences (eg, Khachatoorian et al 2021; for reviews, see Harvey et al 2016; Silva et al 2018). However, the benefits of photo review can be accompanied by a cost. For example, in a study by Koutstaal et al (1999), after carrying out simple actions in the lab (eg, pounding a nail into a block of wood), participants reviewed photos of some of the actions, which boosted recall of those actions on a later test. But recall of non-reviewed actions on that same test was reduced compared to a condition in which participants did not review any photographs, suggesting that selective review of photographs can impair memory for non-reviewed content (see Cinel et al 2018; Henkel and Milliken 2020 for recent evidence illustrating the benefits and costs of reviewing and editing photos on memory).

Researchers have also begun to investigate how the act of taking a photo impacts memory for the photographed event. Henkel (2014) reported a study in which participants toured a museum and were instructed to take photos of some objects and simply look at others. When they had taken a photo of an object during the tour, participants remembered fewer objects and their locations on a later memory test than when they had just looked at an object. Similar results were reported by Tamir et al (2018) in a study where participants toured a church; some participants had cameras and were instructed to take as many photos as they wanted, whereas others toured the church without a camera and took photos. Participants who took photos recalled fewer details of the tour a week later compared with participants who did not.

One possibility is that these impairing effects of taking photos on later memory are attributable to cognitive offloading (Risko and Gilbert 2016), where the participants rely on the photo as a kind of external memory and thus do minimal memory-related processing. Evidence against this idea was obtained in a study by Soares and Storm (2018) in which participants went on a virtual museum tour: they found an impairing effect of 
taking photos on later memory in a condition where participants deleted their photos shortly after taking them. These findings raise the possibility that, rather than cognitive offloading, the activities in which people engage when taking a photo, such as finding the best angle or lighting conditions for taking the photo, could reduce encoding of the object or event and thus impair subsequent memory. However, other evidence indicates that impaired memory is not a necessary consequence of taking a photo of an event: Henkel (2014) reported that the photo-impairment effect was not observed when participants were instructed to zoom in on a specific part of the photographed object. In addition, Barasch et al (2017) reported a photo-enhancement effect on subsequent memory for visual aspects of a museum tour when participants were able to decide for themselves when to take a photo. Taken together, the emerging evidence does not support the simple conclusion that taking a photo necessarily impairs memory for the photographed object or event, but instead paints a more complex picture, indicating that effects on memory depend on such factors as an individual's goals when taking a photo and what aspects of memory for an event are tested (for more detailed review and discussion, see Henkel et al 2021).

\section{Summary and conceptual distinctions}

To summarise, then, there is some evidence from each of the three areas reviewed (Internet, GPS, and photos) that these forms of technology can impair the ability to retain memories over time, but questions remain concerning the reliability of some of the evidence (ie, Internet and computer effects), and there are also data from research on computer effects and photos that highlight conditions under which aspects of memory may be enhanced.

At a more general conceptual level, however, I believe that discussions regarding the effects of the Internet, GPS, and photos on memory are muddled by a failure to specify exactly what is meant when claims such as 'Internet use is killing your memory' are made. Specifically, I suggest that it is important to distinguish among at least three different ways in which technology or media might impair memory (or potentially enhance it; but for the present purposes, the focus is on impairment). I will refer to these as task-specific, domain-specific, and domain-general effects (for discussion of similar conceptual issues regarding near- and far-transfer in brain training programmes, see Simons et al 2016). A task-specific effect would occur when relying on technology impairs memory for the specific task performed, but does not have broader effects. Thus, for example, a task-specific GPS effect would occur if relying on GPS resulted in poor memory for the specific route on which one used GPS, but had no effects on one's memory beyond that specific route. By contrast, a domain-specific effect would occur when relying on technology impairs memory for both the specific task performed and other tasks within a particular domain, but not on tasks outside that domain (by 'domain', I am referring broadly to classes of information and tasks, such as spatial, verbal, or visual, as well as to broadly accepted distinctions among forms of memory, such as working memory, episodic memory, and semantic memory). Continuing with the GPS example, a domain-specific effect would occur if relying on GPS impaired memory for a specific route in which one relied on GPS, and also impaired the ability to establish memories for other routes and spatial layouts even when not using GPS, but did not impact memory abilities for non-spatial information. Finally, a domain-general effect would occur if relying on technology impairs memory broadly for tasks other than the one relied on and in multiple domains of memory. In this scenario, sufficiently extensive reliance on GPS, for instance, would compromise one's ability to retain both spatial information and non-spatial information, such as 
verbal/linguistic information or non-spatial aspects of everyday events (eg, people and objects associated with a specific event).

Viewing the previously discussed studies from the perspective of the aforementioned distinctions, I think that there is solid evidence for an impairing effect of technology at a task-specific level, such as reduced memory for a photographed item (Henkel 2014; Tamir et al 2018) and impaired memory for routes on which one used GPS (Dahmani and Bohbot 2020; Gardony et al 2015). However, I would characterise the evidence for a domain-specific effect as only suggestive and restricted to the studies of GPS, ie, poor spatial memory tentatively linked to lifetime GPS use in one sample of study participants (Dahmani and Bohbot 2020). Finally, I see no evidence for a domain-general effect of technology on memory in any of the studies discussed here. Yet that is the kind of broad impairment typically implied by worries that technology may be 'killing' or 'ruining' memory. Going forward, it will be interesting to see whether such evidence emerges.

\section{Absent-mindedness}

Absent-minded memory failures occur when there is a breakdown at the interface of attention and memory, often resulting in such annoying everyday memory errors as forgetting where we placed our keys, or that we had scheduled an appointment with a friend. Such a breakdown can occur either at the encoding or retrieval stages of memory. The question addressed here is whether or how media and technology impact these manifestations of absent-minded errors.

\section{Mind wandering and media multitasking}

Cognitive studies have long established that dividing attention during encoding, typically by requiring participants to perform an attention-demanding task in addition to encoding target information (eg, a list of words), severely impairs an individual's ability to form a new memory (eg, Craik et al 1996; and see Gardony et al 2015, for evidence that divided attention contributes to impaired memory for a route following GPS use). A growing number of studies have also demonstrated negative effects on memory as a consequence of spontaneous shifts of attention during encoding that occur as a result of mind wandering - ie, when people focus on thoughts that are unrelated to the primary task at hand (for reviews of mind-wandering research, see Smallwood and Schooler 2006; Seli et al 2016). Mind wandering is particularly relevant to educational settings, as a number of studies have demonstrated that it occurs frequently during both classroom and online lectures, and that engaging in mind wandering can impair retention of lecture content (Lindquist and McLean 2011; Risko et al 2012; Szpunar et al 2013; for review, see Schacter and Szpunar 2015). Of particular relevance to this article, negative effects on memory have also been observed as a consequence of media multitasking, ie, diverting attention during a lecture by using a smartphone or laptop. Wammes et al (2019) reported two studies showing that in a live university lecture setting: (a) students often engaged in media multitasking, (b) the frequency of media multitasking increased during the course of the lecture, and (c) more frequent media multitasking was associated with worse retention on quizzes and tests.

Linking back to the distinctions I suggested in the discussion of transience, the findings of Wammes et al (2019) reflect a task-specific effect of media multitasking on subsequent memory for content from a particular lecture, and indeed, other earlier studies had shown similar task-specific effects of media multitasking on memory in educational contexts (eg, Rosen et al 2013; Wood et al 2012). However, we can also ask whether there are additional domain-specific or domain-general effects of media multitasking. For example, do individuals 
who regularly engage in media multitasking develop chronic deficits such that they exhibit memory impairments even when they are not engaging in media multitasking on a particular task? Do such deficits show up in only one domain (eg, educational materials) or are they evident across multiple domains of memory function?

A growing number of studies have examined the relationship between chronic media multitasking and memory performance, and the general finding is that higher levels of media multitasking are often, but not always, associated with poorer memory performance on a variety of tasks - even under task conditions in which participants do not engage in media multitasking (eg, Uncapher et al 2016; for review, see Uncapher and Wagner 2018). As discussed by Uncapher and Wagner (2018), these effects are most likely attributable to lapses of attention that reduce memory performance. A recent study by Madore et al (2020) provides strong evidence on this point. They reported that attentional lapses during the retrieval phase of a laboratory memory task, revealed by measures of pupil diameter and brain electrical activity that have been reliably associated with momentary lapses of attention, were associated with poorer memory performance on the retrieval task. Moreover, responses on a media multitasking questionnaire revealed that higher levels of self-reported media multitasking were associated with increased attentional lapses, leading to worse memory performance during the retrieval task.

The findings of Madore et al (2020) and those of previous studies that have linked high levels of media multitasking with poor memory performance raise the possibility that chronic reliance on media multitasking causes impaired memory. Given that these memory deficits have been observed during tasks on which people are not engaging in media multitasking, the data further suggest a possible domain-general memory impairment. However, as Madore et al (2020), Uncapher et al (2016), and Uncapher and Wagner (2018) are careful to point out, the extant data are correlational, and thus do not allow us to determine definitively whether media multitasking causes attentional failures that result in memory impairments, or whether individuals who start out with poor attention and memory abilities are especially prone to engaging in media multitasking. Sorting out these two possibilities is an important issue to be addressed by future research. It will also be important to assess whether different kinds of media multitasking are more or less likely to lead to absent-minded memory failures (Baumgartner and Wiradhany 2021).

\section{Prospective memory and cognitive offloading}

While concerns that media multitasking might increase attentional failures that produce absent-minded memory errors are justified, it is also important to note that absent-minded errors can be reduced substantially by reliance on external memory aids (ie, cognitive offloading), and that modern media and technology offer effective ways of delivering such aids. For example, research on prospective memory - remembering to carry out intentions in the future - has shown that absent-minded memory errors often occur when cues to carry out an intended action are not present at the time a future action needs to be executed (eg, McDaniel and Einstein 2007). Creating and relying on external reminders significantly improved performance in a naturalistic prospective memory task (Gilbert 2015). A recent meta-analysis of prospective memory studies in middle-aged and older adults revealed overall positive outcomes for external memory aids in enhancing prospective memory (Jones et al 2021). Commonly used external memory aids include smartphones, smartwatches, and Google Calendar, which have proven useful for improving prospective memory performance in individuals with brain injuries 
and disease who are especially prone to absent-minded forgetting (eg, El Haj et al 2020; Jamieson et al 2019; Svoboda et al 2012).

A particularly affecting example of a catastrophic absent-minded memory failure that can be remedied by external memory aids, including some made possible by modern technology, concerns a phenomenon that occurs regularly every summer: well-intentioned parents forget that they have left their infant in a hot car, resulting in the death of the infant. These tragic cases typically result from an unfortunate confluence of circumstances that conspire to produce a seemingly impossible type of absent-minded forgetting, including absorption with personal concerns, reliance on automatic behaviour, and - most critically - lack of a retrieval cue at the moment it is needed to remind a parent that their infant is in the back seat (for more extensive discussion, see Schacter in press, chapt 2; Weingarten 2009). However, effective external reminder systems using modern technology have been developed that can deliver the missing retrieval cue. For example, a device called the Elepho eclip can be attached to a child's car seat and sends both visual and auditory alerts to smartphones in order to remind drivers that there is a baby in the car (see Baldwin 2019).

The main takeaway from this brief overview of external reminders is that technology can be used to help overcome the annoying and sometimes dangerous consequences of absent-mindedness. Thus, while there are legitimate concerns regarding the negative impact of activities such as media multitasking on memory failures that result from attentional lapses, these concerns should be balanced by the realisation that smartphones and related devices that contribute to media multitasking can also play a positive role in combating absent-minded forgetting.

\section{Misattribution and suggestibility}

In the seven sins framework, misattribution (attributing a memory or idea to the wrong source) and suggestibility (implanted memories that result from suggestion or misinformation) are closely related because memory distortions that result from suggestion always involve some type of misattribution. Here I will briefly consider two related sources of media-/technology-related suggestion or misinformation that can result in misattribution: misleading photographs and fake news circulated on social media (for related reviews and discussion, see Clinch et al 2021; Johnson 2007).

In one of the early studies on photos and memory from my lab, Schacter et al (1997) had young adults (on average 18-19 years old) and older adults (on average in their late sixties) watch a videotaped sequence of actions, and then view 'true photographs' (ie, photos of actions they had seen earlier in the videotape) and 'false photographs' (ie, photos of novel actions from a similar videotape that they had not seen earlier). On a later test, older but not younger adults were more likely to falsely remember that a novel action had occurred in the videotape after reviewing a photo that depicted the action.

Subsequent research using a variety of experimental procedures has revealed that photographs can help to create suggested false memories in young adults, too. In several studies, young adults viewed manipulated photographs depicting events that had not actually occurred in the participants' pasts, together with photos depicting events that had actually occurred. After attempting to recall the depicted events in several interviews, a significant proportion of participants claimed to remember the false events (eg, Garry and Wade 2005; Wade et al 2002; see also, Lindsay et al 2004). Nash et al (2009) had participants watch an experimenter perform simple actions in the laboratory and then perform those actions themselves. After participants viewed doctored videos suggesting that they had performed additional actions by showing the experimenter performing those 
actions in the presence of the participant, participants were subsequently more likely to falsely remember that they had performed the suggested action themselves.

In experiments by St Jacques and Schacter (2013; see also, St Jacques et al 2013), participants toured a museum equipped with a wearable camera that took photos of objects encountered during specific stops on the tour. On a later test, participants were more likely to falsely remember a novel photo of an object they had not seen on the tour after they viewed several photos of related objects that exactly matched either the temporal sequence or visual perspective in which those objects appeared during the tour, compared with when they saw photos of objects that did not match either the previously viewed temporal sequence or visual perspective. The matching photos were thought to more strongly reactivate the tour context, thus contributing to a false sense of having previously seen the novel object.

The foregoing findings highlight ways in which photos can contribute to misattributed memories of past personal events. Other studies show that photos can also contribute to inaccurate memories of public events. For example, Sacchi et al (2007) found that after viewing digitally manipulated photographs of the 1989 Tiananmen Square protest in Beijing and a 2003 protest against the Iraq War in Rome, participants recalled these events differently than those who saw the actual photograph. After viewing manipulated photos, participants recalled a larger number of people in the Tiananmen Square events and recalled more violence in the Rome event, in line with suggestions conveyed by the misleading photographs. Garry et al (2007) found that showing people photos of a village damaged by a hurricane led them to falsely remember more information about death and injury in an accompanying newspaper article than participants who read the same article but saw a photo of the village before the hurricane hit. These and other studies (for detailed review, see Clinch et al 2021) show that misleading or manipulated photos and videos can serve as sources of suggestion that result in misattributed false memories.

These findings are relevant to contemporary concerns about the impact of fake news on beliefs and memories, which have risen dramatically since the 2016 Presidential election in the United States, both in public discussions and in psychological research (for psychological perspectives, see Brashier and Marsh 2020; Brashier and Schacter 2020; Pennycook and Rand 2019, 2020, 2021). Can fake news photos or headlines give rise to suggested memories of events that did not actually happen? Strange et al (2011) showed that when photographs were paired with fake news headlines (eg, Blair Under Fire for Botched Baghdad Rescue Attempt; Won't Step Down), participants were subsequently more likely to falsely remember the fake news event than when no photos accompanied the headline. A recent study by Murphy et al (2019) provides further compelling evidence. A week before a controversial May 2018 referendum that resulted in the repeal of the eighth amendment to the constitution of Ireland, which protects the right to life of the unborn and is responsible for highly restrictive abortion laws, Murphy et al administered an online survey to over 3000 adults. The survey included photos and headlines of four true and two fake new stories related to either the 'yes' campaign, which favoured repealing the eighth amendment, or to the 'no' campaign, which wanted to preserve it. There were two versions of each of the fake news stories, one that reflected negatively on the 'yes' side and another that reflected negatively on the 'no' side. Murphy et al probed whether participants remembered the events, and they found that nearly half of the participants claimed to remember the event depicted in at least one of the fake photos/headlines. Moreover, a higher percentage of 'yes' supporters reported a false memory for fake news about the 'no' side, and the opposite was observed for 'no' supporters. In addition to providing evidence for a suggested false memory of fake news induced by a headline and photo that could plausibly be encountered on the Internet, this latter finding also indicates the influence of another memory sin: bias, where memory is skewed by pre-existing 
beliefs, knowledge, and feelings (for additional related evidence, see Levine et al 2021; and for general discussion, see Schacter in press).

Linking back to the distinction made earlier between task-specific, domain-specific, and domain-general effects, all of the evidence considered in this section falls squarely within the purview of task-specific effects, ie, photos and Internet headlines can produce distorted or entirely false memories for a specific event, but there is no evidence that they produce broader changes such that people are more generally susceptible to suggestion and misattribution as a consequence of exposure to these forms of media. We do know that some individuals are more susceptible than others to particular kinds of false memories attributable to misinformation (eg, Zhu et al 2010), semantic associations (eg, Clancy et al 2000; Dewhurst et al 2018), and fake news about the Covid-19 pandemic (Greene and Murphy 2020). However, in a study that examined participants' performance on three well-established laboratory false memory tasks, Nichols and Loftus (2019) failed to find evidence that some individuals are consistently more prone to false memories across the three tasks. In light of these uncertainties, more research examining possible links between habitual exposure to misinformation via photos and fake news and the development of a general susceptibility to false memories is worth exploring.

\section{Concluding comments}

In this article, I have discussed the nature and extent of the impact of media and technology on transience, absent-mindedness, misattribution, and suggestibility. The evidence shows that the nature and extent of this impact depends on both the type of media or technology that people use, and the specific memory process under consideration. Negative impacts have been documented, but they are mostly what I have called processspecific effects, with limited evidence for domain-specific effects and no evidence for domain-general effects. Moreover, some positive impacts have also been documented, such as some aspects of photo review for reducing transience and technology-assisted offloading for absent-mindedness. Thus, we should approach broad claims about the damaging effects of technology and media on memory with caution.

My approach has been guided by the seven sins framework for classifying memory errors, which is rooted primarily in cognitive psychology and cognitive neuroscience. However, in the interdisciplinary spirit of $M M M$, I look forward to future discussions of these issues from the perspective of the many other disciplines that have much to offer concerning both the theoretical and societal implications of media and technology influences on forgetting and distortion in human memory.

Acknowledgements. I thank Nadia Brashier, Adam Bulley, Ethan Harris, Kevin Madore, and Hannah Schacter for helpful comments on an earlier draft of the manuscript.

Financial support. The author is supported by grants from the National Institute on Aging [grant no. R01 AG008441] and the National Institute of Mental Health [grant no. R01MH060941]. The funders had no role in the decision to publish, or with preparation of the manuscript.

Conflict of interests. The author declares none.

\section{References}

Baldwin D (2019) Life-saving car seat alarms that remind parents there's a baby in the back seat. Available at https:// www.fatherly.com/gear/best-car-seat-alarms/. Accessed June 14, 2021.

Barasch A, Diehl K, Silverman J and Zauberman G (2017) Photographic memory: The effects of volitional photo taking on memory for visual and auditory aspects of an experience. Psychological Science 28, 1056-1066. https://doi.org/10.1177/0956797617694868. 
Bartlett FC (1932) Remembering: A Study in Experimental and Social Psychology. Cambridge: Cambridge University Press.

Baumgartner SE and Wiradhany W (2021) Not all media multitasking is the same: The frequency of media multitasking depends on cognitive and affective characteristics of media combinations. Psychology of Popular Media. https://doi.org/10.1037/ppm0000338.

Brashier NM and Marsh EJ (2020) Judging truth. Annual Review of Psychology 71, 499-515. https://doi.org/10. 1146/annurev-psych-010419-050807.

Brashier NM and Schacter DL (2020) Aging in an era of fake news. Current Directions in Psychological Science 29, 316-323. https://doi.org/10.1177/0963721420915872.

Camerer CF, et al. (2018) Evaluating the replicability of social science experiments in Nature and Science between 2010 and 2015. Nature Human Behavior 2, 637-644. https://doi.org/10.1038/s41562-018-0399-z.

Cinel C, Mack CC and Ward G (2018) Towards augmented human memory: Retrieval-induced forgetting and retrieval practice in an interactive, end-of-day review. Journal of Experimental Psychology: General 147, 632-661. http://dx.doi.org/10.1037/xge0000441.

Clancy SA, Schacter DL, McNally RJ and Pitman RK (2000) False recognition in women reporting recovered memories of sexual abuse. Psychological Science 11, 26-31. https://doi.org/10.1111/1467-9280.00210.

Clinch S, Mack CC, Ward G and Steeds M (2021) Technology-mediated memory impairment. In Dingler T and Niforatos E (eds), Technology-Augmented Perception and Cognition. Switzerland: Springer Nature, 71-124. https:// doi.org/10.1007/978-3-030-30457-7_4.

Coughlan S (2015) Digital dependence 'eroding human memory'. BBC News. Available at https://www.bbc.com/ news/education-34454264. Accessed June 14, 2021.

Craik FIM, Govoni RR, Naveh-Benjamin M and Anderson ND (1996) The effects of divided attention on encoding and retrieval processes in human memory. Journal of Experimental Psychology: General 125, 159-180. https:// doi.org/10.1037/0096-3445.125.2.159.

Dahmani L and Bohbot VD (2020) Habitual use of GPS negatively impacts spatial memory during self-guided navigation. Scientific Reports, 10, Article number: 6310. https://doi.org/10.1038/s41598-020-62877-0

Dewhurst SA, Anderson RJ, Berry DM and Garner SR (2018) Individual differences in susceptibility to false memories: The effect of memory specificity. Quarterly Journal of Experimental Psychology 71, 1637-1644. https://doi.org/10.1080/17470218.2017.1345961.

Ebbinghaus H (1964 [1885]) Über das Gedächtnis [Memory]. Leipzig, Germany: Duncker and Humblot. [English translation, Dover Press, 1964].

El Haj M, Moustafa AA, Gallouj K and Allain P (2020) Cuing prospective memory with smartphone-based calendars in Alzheimer's disease. Archives of Clinical Neuropsychology, 36, 316-321. https://doi.org/10.1093/arclin/ acaa060

Finley JR, Naaz F and Goh FW (2018) Memory and Technology: How We Use Information in the Brain and the World. Cham, Switzerland: Springer.

Gardony AL, Brunyé TT and Taylor HA (2015) Navigational aids and spatial memory impairment: The role of divided attention. Spatial Cognition \& Computation 15, 246-284. https://doi.org/10.1080/13875868.2015.1059432

Garry M and Wade KA (2005) Actually, a picture is worth less than 45 words: Narratives produce more false memories than photographs. Psychonomic Bulletin \& Review 12, 359-366. https://doi.org/10.3758/BF03196385.

Garry M, Srange D, Bernstein DM and Kinzett T (2007) Photographs can distort memory for the news. Applied Cognitive Psychology 21, 995-1004. https://doi.org/10.1002/acp.1362.

Giebl S, Mena S, Storm BC, Bjork EL and Bjork RA (2020) Answer first or Google first? Using the Internet in ways that enhance, not impair, one's subsequent retention of needed information. Psychology Learning \& Teaching 20, 58-75. https://doi.org/10.1177/1475725720961593

Gilbert SJ (2015) Strategic offloading of delayed intentions into the external environment. Quarterly Journal of Experimental Psychology 68, 971-992. https://doi.org/10.1080/17470218.2014.972963.

Greene CM and Murphy G (2020) Individual differences in susceptibility to false memories for COVID-19 fake news. Cognitive Research: Principles and Implications 5. Article number 63. https://doi.org/10.1186/s41235-020-00262-1.

Grinschgl S, Papenmeier F and Meyerhoff HS (2021) Consequences of cognitive offloading: Boosting performance but diminishing memory. Quarterly Journal of Experimental Psychology. https://doi.org/10.1177/ 17470218211008060.

Harvey M, Langheinrich M and Ward G (2016) Remembering through lifelogging: A survey of human memory augmentation. Pervasive and Mobile Computing 27, 14-26. https://doi.org/10.1016/j.pmcj.2015.12.002

Henkel LA (2014) Point-and-shoot memories: The influence of taking photos on memory for a museum tour. Psychological Science 25, 396-402. https://doi.org/10.1177/0956797613504438 
Henkel LA and Milliken A (2020) The benefits and costs of editing and reviewing photos of one's experiences on subsequent memory. Journal of Applied Research in Memory and Cognition 9, 480-494. https://doi.org/10.1016/j. jarmac.2020.07.002.

Henkel LA, Nash RA and Paton JA (2021) 'Say Cheese!' How taking and viewing photos can shape memory and cognition. In Lane S and Atchley B (eds), Human Capacity in the Attention Economy. Washington, DC: American Psychological Association, 103-133.

Hesselman G (2020) No conclusive evidence that difficult general knowledge questions cause a 'Google Stroop effect'. A replication study. PeerJ 8, e10325. https://doi.org/10.7717/peerj.10325.

Jamieson M, et al. (2019) The use of a smartwatch as a prompting device for people with acquired brain injury: A single case study experimental design. Neuropsychological Rehabilitation 29, 513-533. https://doi.org/10.1080/ 09602011.2017.1310658.

Javadi A-H, et al. (2017) Hippocampal and prefrontal processing of network topology to simulate the future. Nature Communications 8, 14652. https://doi.org/10.1038/ncomms14652.

Johnson MK (2007) Reality monitoring and the media. Applied Cognitive Psychology 21, 981-993. https://doi.org/ 10.1002/acp.1393.

Jones WE, Benge JF and Scullin MK (2021) Preserving prospective memory in daily life: A systematic review and meta-analysis of mnemonic strategy, cognitive training, external memory aid, and combination interventions. Neuropsychology 35, 123-140. https://doi.org/10.1037/neu0000704.

Kahn AS and Martinez TM (2020) Text and you might miss it? Snap and you might remember? Exploring 'Google effects on memory' and cognitive self-esteem in the context of Snapchat and messaging. Computers in Human Behavior 104, 106166. https://doi.org//10,1016/j.chb.2019.106166.

Khachatoorian N, Loveday C, Dima D, Illingworth S, Conway MA and Hanschel C (2021) A behavioural and ERP investigation of wearable camera photo review in autobiographical memory. Memory 29, 224-233. https:// doi:10.1080/09658211.2021.1880601.

Konishi K and Bohbot VD (2013) Spatial navigation strategies correlate with gray matter of the hippocampus of healthy older adults tested in a virtual maze. Frontiers in Aging Neuroscience 5. https://doi.org/10.3389/fnagi. 2013.00001.

Koutstaal W, Schacter DL, Johnson MK, Angell KE and Gross MS (1998) Post event review in older and younger adults: Improving memory accessibility of complex everyday events. Psychology and Aging 13, 277-296. https:// doi.org/10.1037/0882-7974.13.2.277.

Koutstaal W, Schacter DL, Johnson MK and Galluccio L (1999) Facilitation and impairment of event memory produced by photograph review. Memory \& Cognition 27, 478-493. https://doi.org/10.3758/BF03211542.

Levine LJ, et al. (2021) Remembering facts versus feelings in the wake of political events. Cognition and Emotion. https://doi.org/10.1080/02699931.2021.1910496

Lindquist SL and McLean JP (2011) Daydreaming and its correlates in an educational environment. Learning and Individual Differences 21, 158-167. https://doi.org/10.1016/j.lindif.2010.12.006

Lindsay SD, Hagen L, Read JD, Wade KA and Garry M (2004) True photographs and false memories. Psychological Science 15, 149-154. https://doi.org/10.1111/j.0956-7976.2004.01503002.x.

Madore KP, et al. (2020) Memory failure predicted by attention lapsing and media multitasking. Nature 587, 87-91. https://doi.org/10.1038/s41586-020-2870-z.

Maguire EA, et al. (2000) Navigation-related structural change in the hippocampi of taxi drivers. Proceedings of the National Academy of Sciences 97, 4398-4403. https://doi.org/10.1073/pnas.070039597.

Marsh EJ and Rajaram S (2019) The digital expression of the mind: Implications of Internet usage for memory and cognition. Journal of Applied Research in Memory and Cognition 8, 1-14. https://doi.org/10.1016/j.jarmac.2018. 11.001 .

McDaniel MA and Einstein Go (2007) Prospective Memory: An Overview and Synthesis. Thousand Oaks, CA: Sage Publications.

Murphy G, Loftus EF, Grady RH, Levine LJ and Greene CM (2019) False memories for fake news during Ireland's abortion referendum. Psychological Science 30, 1449-1459. https://doi.org/10.1177/0956797619864887.

Nash RA, Wade KA and Lindsay DS (2009) Digitally manipulating memory: Effects of doctored videos and imagination in distorting beliefs and memories. Memory \& Cognition 37, 414-424. https://doi.org/10.3758/ MC.37.4.414

Nichols RM and Loftus EF (2019) Who is susceptible to false memory tasks? Memory 27, 962-984. https://doi. org/10.1080/09658211.2019.1611862.

Pennycook G and Rand DG (2019) Lazy, not biased: Susceptibility to partisan fake news is better explained by lack of reasoning than by motivated reasoning. Cognition 188, 39-50. https://doi.org/10.1016/j.cognition.2018. 06.011. 
Pennycook G and Rand DG (2020) Who falls for fake news? The roles of bullshit receptivity, overclaiming, familiarity, and analytic thinking. Journal of Personality 88, 185-200. https://doi.org/10.1111/jopy.12476.

Pennycook G and Rand DG (2021) The psychology of fake news. Trends in Cognitive Sciences 25, 388-402. https:// doi.org/10.1016/j.tics.2021.02.007.

Peterson A (2015). How the Internet is ruining your memory. The Washington Post. Available at https://www. washingtonpost.com/news/the-switch/wp/2015/07/01/how-the-internet-is-ruining-your-memory/. Accessed June 14, 2021.

Poeppel D, Mangun GR and Gazzaniga M (Eds) (2020) The Cognitive Neurosciences, 6th edn. Cambridge, MA: MIT Press.

Risko EF and Gilbert SJ (2016) Cognitive offloading. Trends in Cognitive Sciences 20, 676-688. https://doi.org/10. 1016/j.tics.2016.07.002.

Risko EF, Anderson N, Sarwal A, Engelhardt M and Kingstone A (2012) Everyday attention: Variation in mind wandering and memory in a lecture. Applied Cognitive Psychology 26, 234-242. https://doi.org/10.1002/acp.1814.

Robitzski D (2019) Wait, what? New research says Internet use is killing our brains. The Byte. Available at https:// futurism.com/the-byte/internet-killing-memory. Accessed June 14, 2021.

Rosen LD, Carrier LM and Cheever NA (2013) Facebook and texting made me do it: Media-induced task switching while studying. Computers in Human Behavior 29, 948-958. https://doi.org/10.1016/j.chb.2012.12.001.

Runge Y, Frings C and Tempel T (2019) Saving-enhanced performance: Saving items after study boosts performance in subsequent cognitive demanding tasks. Memory 27, 1462-1467. https://doi:10.1080/096582112.2019. 1654520.

Runge Y, Frings C and Tempel T (2020) Specifying mechanisms behind benefits of saving-enhanced memory. Psychological Research. https://doi.org/10.1007/s00426-020-01341-0.

Sacchi DLM, Agnoli F and Loftus EF (2007) Changing history: Doctored photographs affect memory for past public events. Applied Cognitive Psychology 21, 1005-1022. https://doi.org/10.1002/acp.1394.

Schacter DL (1999) The seven sins of memory: Insights from psychology and cognitive neuroscience. American Psychologist 54, 182-203. https://doi.org/10.1037/0003-066X.54.3.182.

Schacter DL (2001) The Seven Sins of Memory: How the Mind Forgets and Remembers. New York and Boston: Houghton Mifflin.

Schacter DL (2021) The seven sins of memory: An update. Memory. https://doi.org/10.1080/09658211.2021. 1873391.

Schacter DL (in press) The Seven Sins of Memory: How the Mind Forgets and Remembers (Revised Edition). New York and Boston: Houghton Mifflin Harcourt.

Schacter DL and Szpunar KK (2015) Enhancing attention and memory during video-recorded lectures. Scholarship of Teaching and Learning in Psychology 1, 60-71. https://doi.org/10.1037/stlo000011.

Schacter DL, Koutstaal W, Johnson MK, Gross M and Angell KA (1997) False recollection induced via photographs: A comparison of older and younger adults. Psychology and Aging 12, 203-215. https://doi.org/10.1037/ 0882-7974.12.2.203.

Seli P, Risko EF, Smilek D and Schacter DL (2016) Mind-wandering with and without intention. Trends in Cognitive Sciences 20, 605-617. https://doi.org/10.1016/j.tics.2016.05.010.

Sharifian N and Zahodne LB (2020) Social media bytes: Daily associations between social media use and everyday memory failures across the adult life span. Journals of Gerontology: Psychological Sciences 75, 540-548. https:// doi.org/10.1093/geronb/gbz005.

Silva AR, Pinho MS, Macedo L and Moulin CJA (2018) A critical review of the effects of wearable cameras on memory. Neuropsychological Rehabilitation 28, 117-141. https://doi.org/10.1080/09602011.2015.1128450.

Simons DJ, et al. (2016) Do 'brain training' programs work? Perspectives on Psychological Science 17, $103-186$. https://doi:10.1177/1529100616661983.

Slotnick SD (2017) Cognitive Neuroscience of Memory. Cambridge: Cambridge University Press.

Smallwood J and Schooler JW (2006) The restless mind. Psychological Bulletin 132, 946-958. https://doi.org/10. 1037/0033-2909.132.6.946.

Soares JS and Storm BC (2018) Forget in a flash: A further investigation of the photo-taking-impairment effect. Journal of Applied Research in Memory and Cognition 7, 154-160. https://doi.org/10.1016/j.jarmac.2017.10.004.

Sparrow B (2018) The importance of contextual relevance. Nature Human Behaviour 2, 607. https://doi.org/10. 1038/s41562-018-0411-7.

Sparrow B, Liu J and Wegner DM (2011) Google effects on memory: Cognitive consequences of having information at our fingertips. Science 333, 776-778. doi:10.1126/science.1207745.

St Jacques PL and Schacter DL (2013) Modifying memory: Selectively enhancing and updating personal memories for a museum tour by reactivating them. Psychological Science 24, 537-543. https://doi.org/10.1177/ 0956797612457377. 
St Jacques PL, Olm C and Schacter DL (2013) Neural mechanisms of reactivation-induced updating that enhance and distort memory. Proceedings of the National Academy of Sciences USA 110, 19671-19678. https://doi.org/10. 1073/pnas.1319630110.

Storm BC and Stone SM (2015) Saving enhanced memory: The benefits of saving on the learning and remembering of new information. Psychological Science 26, 182-188. https://doi.org/10.1177/0956797614559285.

Strange D, Garry M, Bernstein D and Lindsay DS (2011) Photographs cause false memories for the news. Acta Psychologica 136, 90-94. doi:10.1016/j.actpsy.2010.10.006.

Stuart SC (2019). Is technology destroying our memory? PC Magazine. Available at https://www.pcmag.com/ news/is-technology-destroying-our-memory. Accessed June 14, 2021.

Svoboda E, Richards B, Leach L and Mertens V (2012) PDA and smartphone use by individuals with moderate-to-severe memory impairment: Application of a theory-driven training programme. Neuropsychological Rehabilitation 22, 408-427. https://doi.org/10.1080/09602011.2011.652498.

Szpunar KK, Kahn NY and Schacter DL (2013) Interpolated memory tests reduce mind wandering and improve learning of online lectures. Proceedings of the National Academy of Sciences USA 110, 6313-6317. https://doi.org/ 10.1073/pnas.1221764110.

Tamir DI, Templeton EM, Ward AF and Zaki J (2018) Media usage diminishes memory for experiences. Journal of Experimental Social Psychology 76, 161-168. https://doi.org/10.1016/j.jesp.2018.01.006.

Uncapher MR and Wagner AD (2018) Minds and brains of media multitaskers: Current findings and future directions. Proceedings of the National Academy of Sciences 40, 9889-9896. https://doi.org/10.1073/pnas.1611612115.

Uncapher MR, Thieu MK and Wagner AD (2016) Media multitasking and memory: Differences in working memory and long-term memory. Psychonomic Bulletin and Review 23, 483-490. https://doi.org/10.3758/s13423-0150907-3.

Wade KA, Garry M, Read JD and Lindsay DS (2002) A picture is worth a thousand lies. Psychonomic Bulletin and Review 9, 597-603. https://doi.org/10.3758/BF03196318.

Wammes JD, Ralph BCW, Mills C, Bosch N, Duncan TL and Smilek D (2019) Disengagement during lectures: Media multitasking and mind wandering in university classrooms. Computers \& Education 132, 76-89. https://doi.org/10.1016/j.compedu.2018.12.007.

Weingarten G (2009). Fatal distraction. Washington Post. Available at https://www.washingtonpost.com/lifestyle/ magazine/fatal-distraction-forgetting-a-child-in-thebackseat-of-a-car-is-a-horrifying-mistake-is-it-a-crime/ 2014/06/16/8ae0fe3a-f580-11e3-a3a5-42be35962a52_story.html?noredirect=on. Accessed June 14, 2021.

Weisberg SM, Newcombe NS and Chatterjee A (2019) Everyday taxi drivers: Do better navigators have larger hippocampi? Cortex 115, 280-293. https://doi.org/10.1016/j.cortex.2018.12.024.

Wood E, Zivcakova L, Gentile P, Archer K, De Pasquale D and Nosko A (2012) Examining the impact of off-task multi-tasking with technology on real-time classroom learning. Computers \& Education 58, 365-374. https://doi. org/10.1016/j.compedu.2011.08.029.

Woollett K and Maguire EA (2011) Acquiring 'the Knowledge' of London's layout drives structural brain changes. Current Biology 21, 2109-2114. https://doi.org/10.1016/j.cub.2011.11.018.

Zhu B, et al. (2010) Individual differences in false memory from misinformation: Cognitive factors. Memory 18, 543-555. https://doi.org/10.1080/09658211.2010.487051.

Daniel L Schacter is William R Kenan, Jr. Professor of Psychology at Harvard University. His research examines the cognitive neuroscience of human memory, imagination, and future thinking. He is the author of numerous scientific articles and several books, most recently an updated edition of his 2001 book, The Seven Sins of Memory.

Cite this article: Schacter DL (2022). Media, technology, and the sins of memory. Memory, Mind \& Media 1, e1, 1-15. https://doi.org/10.1017/mem.2021.3 